\title{
Caco-2 cell-based Antioxidant Activity of 36 Vegetables Commonly Consumed in China
}

\author{
Hongxia Wan ${ }^{1}$, Renbin Liu ${ }^{2}$, Haiyan Sun ${ }^{1}$, Xiangying $\mathrm{Yu}^{1}$, Yan Li ${ }^{1}$, Yanli Cong ${ }^{1}$, Dong Liu ${ }^{1, *}$ \\ ${ }^{1}$ Shenzhen Key Laboratory of Fermentation, Purification and Analysis, Shenzhen Polytechnic, Shenzhen, China \\ ${ }^{2}$ Department of Traditional Chinese Medical, Shiyan People’s Hospital, Shiyan, China \\ *Corresponding author: liudongsz@szpt.edu.cn
}

Received March 07, 2014; Revised March 17, 2014; Accepted March 19, 2014

\begin{abstract}
Determination of antioxidant activity using biologically relevant assay is important to screen vegetables for potential health benefits. This study was to evaluate the Caco-2 cell-based antioxidant activity (CAA) of 36 vegetables commonly consumed in China. Total phenolics, total flavonoids and oxygen radical absorbance capacity (ORAC) for selected vegetables were also measured to be compared with CAA values. The results showed that there was a large variation among different vegetables in CAA values with the highest value of $37 \pm 3.7 \mu$ mol of quercetin equivalents (QE) /100 g in lotus root and lowest value of $0.376 \pm 0.053 \mu \mathrm{mol}$ of QE/100 g in green bell pepper, and 23 vegetables were of unquantifiable CAA values due to their low activities. Correlation analysis showed that CAA values were significantly correlated to total phenolics $(\mathrm{R}=0.516, \mathrm{p}<0.01)$ and ORAC values $(\mathrm{R}=0.350, \mathrm{p}<0.05)$, suggesting a better predictor of total phenolics for the CAA of vegetables. The data obtained could be useful for consumers to plan antioxidant rich diets and for nutritionists to estimate health benefits of vegetables from daily intake.
\end{abstract}

Keywords: vegetables, Caco-2 cell-based antioxidant activity (CAA), phenolic content, flavonoid content, oxygen radical absorbance capacity (ORAC)

Cite This Article: Hongxia Wan, Renbin Liu, Haiyan Sun, Xiangying Yu, Yan Li, Yanli Cong, and Dong Liu, "Caco-2 cell-based Antioxidant Activity of 36 Vegetables Commonly Consumed in China." Journal of Food and Nutrition Research, vol. 2, no. 2 (2014): 88-95. doi: 10.12691/jfnr-2-2-5.

\section{Introduction}

Free radicals, reactive molecules generated in the body as a result of oxidative metabolism, are involved in the development of different ailments, such as cardiovascular disease, diabetes and cancer [1,2]. The body has an antioxidant defense system to protect itself against free radicals. Under normal condition, equilibrium is maintained between the generation of free radicals and their elimination by the antioxidant defense system. However, an unbalance can occur when the generation of free radicals is greater than the antioxidant defense capacity of the body, which leads to the presence of excessive free radicals, thus causing the oxidative damage of biomacromolecules such as lipids, proteins and DNA, and then leading the body toward a pathological state [3].

Vegetables are rich in bioactive compounds such as flavonoids, phenolic acids, vitamins, and carotenoids. The combined phytochemicals in vegetables have been reported to possess strong antioxidant activity [4]. Numerous studies have shown that antioxidant activity obtained from vegetable consumption could decrease the risk of developing several pathologies such as cardiovascular diseases, cancer and aging $[5,6]$. Thus, it is important to evaluate the antioxidant potential of vegetables using biological relevant assay so as to truly predict their health benefits in vivo. Our laboratory has developed a new quantitative cellular antioxidant activity assay based on Caco-2 cell model (shown in another submitted manuscript) [7], which was shown to possess good biological relevance by comparing with the results from animal experiment. This assay utilizes 2',7'dichlorofluorescin diacetate (DCFH-DA) as a probe in cultured Caco-2 cells, which is deacetylated by cellular esterases to form polar 2',7'-dichlorofluorescin (DCFH) and then fluoresces when oxidized by peroxyl radicals to dichlorofluorescein (DCF). It was developed in response to a need for a more biological relevant method than the chemistry antioxidant activity assay and other cell-based assays based on the assumption that Caco-2 cellular model could reflect intestinal absorption characteristics of antioxidants before showing antioxidant effect in the body since good correlation was observed between the in vitro absorption in Caco-2 cellular model and in vivo intestinal absorption $[8,9]$.

The antioxidant activity of vegetables has been investigated using many chemistry antioxidant activity assays, such as ABTS/DPPH radical scavenging activity assay, ferric reducing/antioxidant power (FRAP) assay, total radical-trapping antioxidant parameter (TRAP) assay, total oxyradical scavenging capacity (TOSC) assay and oxygen radical absorbance capacity (ORAC) assay $[10,11,12,13,14]$; and cellular antioxidant activity assay [15], which used HepG2 cell-based model and was 
employed to survey the antioxidant activity of commonly consumed vegetables in America.

Considering that there was no report on the cellular antioxidant activity of vegetables commonly consumed in China, and the good biological relevance of Caco-2 cellbased antioxidant activity (CAA) assay was proved in our previous experiment, the objective of this study was to determine the Caco-2 cell-based antioxidant activity of 36 commonly consumed vegetables in China. The total phenolics, total flavonoids, and ORAC values for the selected vegetables were also measured to be compared with CAA values.

\section{Materials and Methods}

\subsection{Chemicals}

Quercetin, gallic acid, (+)-catechin hydrate, fluorescein disodium salt, 6-hydroxy-2,5,7,8-tetramethylchroman-2carboxylic acid (Trolox), 2',7'-dichlorofluorescin diacetate (DCFH-DA), 2,2'-azobis(2-methylpropionamidine) dihydrochloride (AAPH), 4-(2-hydroxyethyl)-1-piperazine ethane sulfonic acid (Hepes), non-essential amino acid $(100 \times)$, trypan blue solution $(0.4 \%)$, and dimethyl sulfoxide (DMSO) were purchased from Sigma-Aldrich, Inc. (St. Louis, MO). Caco-2 colon adenocarcinoma cells were obtained from the American Type Culture Collection (ATCC) (Rockville, MD). Dulbecco's Modified Eagle Medium (DMEM), fetal bovine serum (FBS), Hanks' Balanced Salt Solution (HBSS, $1 \times$ ), pen strep solution $(100 \times)$, and $0.05 \%$ Trypsin-EDTA were purchased from Gibco Life Technologies (Grand Island, NY). Other reagents were obtained from damao chemical reagent factory of Tianjin (Tianjin, CN).

\subsection{Preparation of Vegetable Extracts}

A total of 36 vegetables (balsam pear, bottle gourd, broccoli, carrot, cauliflower, celery, Chinese cabbage, Chinese chive, Chinese flowering cabbage, Chinese kale, cucumber, garlic sprout, green bean, green bell pepper, green chili pepper, green pumpkin, leaf lettuce, lettuce, long bean, lotus root, malabar spinach, potato, purple cabbage, purple eggplant, purple onion, red edible amaranth, red hyacinth bean, romaine lettuce, Shanghai pakchoi, shiitake mushroom, spinach, tomato, towel gourd, water spinach, wax gourd and white turnip) were purchased from local market. Extracts were prepared from the edible part of fresh vegetables according to the procedures described previously [16] with slight modifications in our laboratory. Briefly, $100 \mathrm{~g}$ of fresh weight of the edible part of vegetables were weighed and homogenized with $200 \mathrm{~mL}$ chilled 80\% acetone using a chilled Philips blender for 3 min. The slurry was then further homogenized using an IKA dispersion tool (T25 digital Ultra-Turrax, IKA Works, Inc., Staufen, Germany) for an additional $5 \mathrm{~min}$ in the ice bath. The solution was filtered through No.1 Whatman paper on a Buchner funnel under vacuum. The filtrate was collected, and in twice, the residue was homogenized with $200 \mathrm{~mL}$ of chilled $80 \%$ acetone using the dispersion tool for $8 \mathrm{~min}$ in the ice bath. The filtration was also performed in twice. Three aliquots of filtrate were pooled and evaporated by a rotary evaporator under vacuum at $45{ }^{\circ} \mathrm{C}$ until approximately
$90 \%$ of the filtrate had evaporated. The filtrate was then reconstituted in deionized water and kept frozen at $-80{ }^{\circ} \mathrm{C}$ until analysis. Control extracts were prepared using the same extraction solvents and procedures without vegetables.

\subsection{Cell Culture}

Caco-2 cells were grown in growth medium (high glucose DMEM supplemented with 10\% FBS, $10 \mathrm{mM}$ Hepes, 1\% non-essential amino acid, 100 units $/ \mathrm{mL}$ penicillin, $100 \mu \mathrm{g} / \mathrm{mL}$ streptomycin) and were maintained at $37^{\circ} \mathrm{C}$ in $5 \% \mathrm{CO}_{2}$. Cells used in this study were between passages 10 and 30 .

\subsection{Cytotoxicity}

The cytotoxicity of vegetables toward Caco-2 cells was measured using the colorimetric methylene blue assay reported previously [17]. Caco-2 cells were seeded at $4 \times$ $10^{4}$ /well on a 96-well microplate in $100 \mu \mathrm{L}$ of growth medium at $37^{\circ} \mathrm{C}$. Twenty-four hours after seeding, the growth medium was removed, and the cells were washed with $100 \mu \mathrm{L}$ of PBS. Then, $100 \mu \mathrm{L}$ of treatment medium (WME supplemented with $2 \mathrm{mM}$ L-glutamine and $10 \mathrm{mM}$ Hepes) containing various concentrations of vegetable extracts were applied to the cells, and the microplates were incubated at $37^{\circ} \mathrm{C}$ for $24 \mathrm{~h}$. The treatment medium was removed, and the cells were washed with PBS. A volume of $50 \mu \mathrm{L} /$ well methylene blue staining solution (98\% HBSS, 0.67\% glutaraldehyde, 0.6\% methylene blue) was applied to each well, and the microplate was incubated at $37^{\circ} \mathrm{C}$ for $1 \mathrm{~h}$. The dye was removed, and the plate was immersed in fresh deionized water until the water was clear. The water was tapped out of the wells, and the microplate was allowed to air-dry briefly before $100 \mu \mathrm{L}$ of elution solution (49\% PBS, 50\% ethanol, $1 \%$ acetic acid) was added to each well. Then the microplate was placed on a bench-top shaker for $20 \mathrm{~min}$ to allow uniform elution. The absorbance was read at $570 \mathrm{~nm}$ with blank subtraction using the Spectra Max M2 spectrophotometer (MD, USA). The median cytotoxic concentration $\left(\mathrm{CC}_{50}\right)$ was calculated for each vegetable.

\subsection{Caco-2 cell-based Antioxidant Activity (CAA) of Vegetable Extracts}

The Caco-2 cell-based antioxidant activity of vegetable extracts was determined using the protocol described previously (shown in another submitted manuscript) [7]. That is, Caco- 2 cells suspension were seeded at a density of $5 \times 10^{4}$ /well on a black, clear-bottom, 96-well microplate in $100 \mu \mathrm{L}$ growth medium/well. Twenty-four hours after seeding, the growth medium was removed and the adherent cells were washed once with $150 \mu \mathrm{L}$ of $1 \times$ PBS. Cells were then incubated for $20 \mathrm{~min}$ with $100 \mu \mathrm{L}$ of antioxidant treatment medium (DMEM containing $10 \mathrm{mM}$ Hepes) containing control extracts, vegetable extracts or quercetin of different concentrations plus $60 \mu \mathrm{M}$ DCFHDA. Treatment medium was removed and the cells were washed once with $150 \mu \mathrm{L}$ of PBS. Cells were then treated with $500 \mu \mathrm{M}$ AAPH in $100 \mu \mathrm{L}$ oxidant treatment medium (HBSS containing $10 \mathrm{mM}$ Hepes) except blank cells, which were treated with oxidant treatment medium containing no AAPH, and the microplate was placed into a 
Spectra Max M5e multifunctional plate reader (Molecular Devices, Sunnyvale, CA) at $37^{\circ} \mathrm{C}$. Fluorescence emitted at $538 \mathrm{~nm}$ with excitation at $485 \mathrm{~nm}$ was measured every 5 min for $90 \mathrm{~min}$. The area under the fluorescence versus time curve (AUC) was integrated to calculate the $\mathrm{EC}_{50}$ values of vegetables as reported previously [17]. EC 50 values were converted to CAA values, which were expressed as micromoles of quercetin equivalents (QE) per $100 \mathrm{~g}$ of fresh vegetable.

\subsection{Determination of Total Phenolic Content}

The total phenolic contents of vegetables were determined from their $80 \%$ acetone extracts by using a colorimetric Folin-Ciocalteu method reported previously [18]. Briefly, a volume of $100 \mu \mathrm{L}$ of the standard gallic acid solution or appropriately diluted vegetable extract was mixed with $0.4 \mathrm{~mL}$ of distilled water in a test tube, followed by the addition of $100 \mu \mathrm{L}$ of Folin-Ciocalteu reagent. After reaction for $6 \mathrm{~min}, 1 \mathrm{~mL}$ of a $7 \% \mathrm{Na}_{2} \mathrm{CO}_{3}$ solution was added and the final volume was adjusted to $2.4 \mathrm{~mL}$ with deionized water. Samples were allowed to stand for $90 \mathrm{~min}$ at room temperature before the absorbance was measured at $760 \mathrm{~nm}$ versus a blank using a Spectra Max M5e multifunctional plate reader. The results were reported as milligrams of gallic acid equivalents (GAE) per $100 \mathrm{~g}$ of fresh vegetable.

\subsection{Determination of Total Flavonoid Content}

The total flavonoid contents of vegetables were measured from their $80 \%$ acetone extracts by using a modified colorimetric method reported previously [19]. Briefly, vegetable extracts were diluted appropriately with deionized water to obtain readings within the standard curve ranges of $0.0-80.0 \mu \mathrm{g}$ of $(+)$-catechin/ $\mathrm{mL}$. Then 2 $\mathrm{mL}$ of the standard $(+)$-catechin solution or diluted vegetable extract was reacted with $75 \mu \mathrm{L} \mathrm{NaNO}_{2}$ solution in a test tube for $6 \mathrm{~min}$, followed by the addition of 150 $\mu \mathrm{L}$ of a $10 \% \mathrm{AlCl}_{3} \cdot 6 \mathrm{H}_{2} \mathrm{O}$ solution. The mixture was allowed to stand for another 5 min before the addition of $0.5 \mathrm{~mL}$ of $1 \mathrm{M} \mathrm{NaOH}$, and the total volume was adjusted to $2.5 \mathrm{~mL}$ with deionized water. The absorbance of final solution at $510 \mathrm{~nm}$ was immediately measured using a Spectra Max M5e multifunctional plate reader. The results were presented as milligrams of catechin equivalents (CE) per $100 \mathrm{~g}$ of fresh vegetable.

\subsection{Determination of Oxygen Radical Scavenging Capacity (ORAC)}

The peroxyl radical scavenging activity of vegetables was measured using the ORAC assay according to the procedures reported previously [20]. Briefly, $20 \mu \mathrm{L}$ of blank, vegetable extracts in $75 \mathrm{mM}$ potassium phosphate buffer ( $\mathrm{pH} 7.4)$, or Trolox standard (6.25-50 $\mu \mathrm{M})$ was added to triplicate wells in a black 96-well plates. No outside wells were used. A volume of $200 \mu \mathrm{L}$ of $0.96 \mu \mathrm{M}$ fluoroscein in potassium phosphate buffer was added to each well and incubated at $37^{\circ} \mathrm{C}$ for $20 \mathrm{~min}$. Then, $20 \mu \mathrm{L}$ of $119 \mathrm{mM}$ AAPH (freshly prepared) in potassium phosphate buffer was added to each well. The microplate was placed into a Spectra Max M5e multifunctional plate reader. Fluorescence intensity at $538 \mathrm{~nm}$ was measured with excitation at $485 \mathrm{~nm}$ every $4.5 \mathrm{~min}$ for 35 cycles. The area under the fluorescence versus time curve (AUC) was integrated to calculate the ORAC values, which were expressed as micromoles of Trolox equivalents (TE) per $100 \mathrm{~g}$ of fresh vegetable.

\subsection{Statistical Analysis}

All data were shown as mean \pm SD for triplicate data from one experiment. Statistical analysis was performed using SPSS V11.0 software (SPSS Inc, Chicago). Differences between means were performed by one-way ANOVA test. Correlations between CAA values and ORAC values, total phenolics or total flavonoids were analyzed using bivariate correlation analysis. Significance was determined at $\mathrm{p}<0.05$.

\section{Results}

\subsection{Total Phenolic Content}

The total phenolic content of vegetables varied from $7.65 \pm 0.71 \mathrm{mg}$ of GAE/100 g in towel gourd to $166 \pm 5$ $\mathrm{mg}$ of GAE/100 $\mathrm{g}$ in Chinese kale, with the difference of 22-fold (Figure 1). Considering a large variation in the total phenolics, the vegetables were divided into four groups, namely very high (> $100 \mathrm{mg}$ of GAE/100 g), high (50 100 mg of GAE/100 g), medium (20 50 mg of GAE/100 g) and low (<20 mg of GAE/100 g). The very high group was represented by Chinese kale, lotus root (157 $\pm 5 \mathrm{mg}$ of GAE/100 g), purple cabbage (149 $\pm 9 \mathrm{mg}$ of $\mathrm{GAE} / 100 \mathrm{~g})$, green chili pepper $(133 \pm 9 \mathrm{mg}$ of GAE/100 g), Chinese flowering cabbage (117 $\pm 8 \mathrm{mg}$ of GAE/100 g) and red hyacinth bean (115 $\pm 5 \mathrm{mg}$ of GAE/100 g). The high group was represented by malabar spinach $(90.6 \pm 7.3 \mathrm{mg}$ of GAE/100 g), broccoli (81.6 \pm 7 $\mathrm{mg}$ of GAE/100 g), spinach (76.3 $\pm 4 \mathrm{mg}$ of GAE/100 g), red edible amaranth (75.3 $\pm 6.2 \mathrm{mg}$ of GAE/100 g), purple eggplant (74.6 $\pm 2.6 \mathrm{mg}$ of GAE/100 g), Shanghai pakchoi $(60.6 \pm 3.8 \mathrm{mg}$ of GAE/100 g), green bell pepper (59.7 \pm $2.8 \mathrm{mg}$ of GAE/100 g), purple onion (58.2 $\pm 2.8 \mathrm{mg}$ of GAE/100 g), Chinese chive (54.2 $\pm 2.6 \mathrm{mg}$ of GAE/100 g) and water spinach $(53.4 \pm 1.7 \mathrm{mg}$ of GAE/100 g). The group with moderate total phenolics was represented by romaine lettuce (48 $\pm 2.2 \mathrm{mg}$ of GAE/100 g), shiitake mushroom (44.4 $\pm 1.94 \mathrm{mg}$ of GAE/100 g), cauliflower $(44.1 \pm 0.28 \mathrm{mg}$ of $\mathrm{GAE} / 100 \mathrm{~g})$, garlic sprout $(42.8 \pm 1.62$ $\mathrm{mg}$ of GAE/100 g), celery (40 $\pm 3.6 \mathrm{mg}$ of GAE/100 g), long beans (36.2 $\pm 3.2 \mathrm{mg}$ of GAE/100 g), potato (34.9 \pm $1.5 \mathrm{mg}$ of GAE/100 g), white ternip (30.4 $\pm 2.4 \mathrm{mg}$ of GAE/100 g), leaf lettuce (24.1 $\pm 0.8 \mathrm{mg}$ of GAE/100 g), green bean $(23.3 \pm 1 \mathrm{mg}$ of GAE/100 g), tomato (21.3 \pm $1.1 \mathrm{mg}$ of GAE/100 g) and Chinese cabbage (20.9 \pm 1.8 $\mathrm{mg}$ of GAE/100 g). The rest vegetables fell in the low group with the ranking order as follows: balsam pear (18.9 $\pm 1.3 \mathrm{mg}$ of GAE/100 g); lettuce, carrot and green pumpkin $(15.4 \pm 1.1,14.4 \pm 1.4$ and $14.4 \pm 1.4 \mathrm{mg}$ GAE/100 g, respectively); bottle gourd (12.6 $\pm 0.6 \mathrm{mg}$ of GAE/100 g); wax gourd and cucumber $(9.68 \pm 0.58$ and $9.56 \pm 0.32 \mathrm{mg}$ of GAE/100 g, respectively); and towel gourd. For the same vegetable investigated, the ranking order in our study was in disagreement with the report by Kaur [21], which might be due to the different origins, cultivars or growing conditions such as climate, soil state. 
For broccoli, spinach and cucumber, total phenolic data in our study corresponded well to previous studies [14,15], which also showed that cucumber ranked low among selected vegetables in total phenolics. The low total phenolic content of cucumber among vegetables was also observed in other studies [13,21,22].

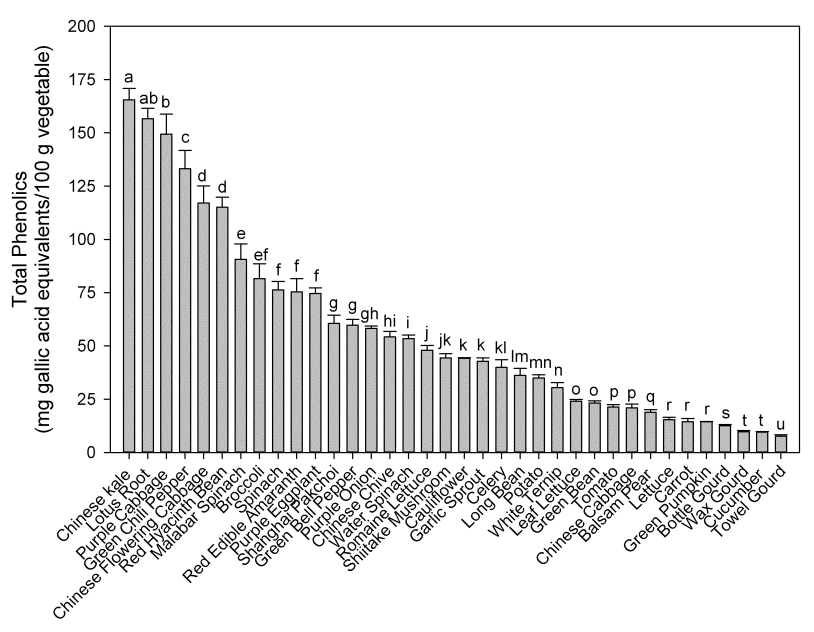

Figure 1. Total phenolic content of selected vegetables (mean $\pm S D, n=$ $3)$. Bars with no letters in common are significantly different $(\mathrm{p}<0.05)$.

\subsection{Total Flavonoid Content}

The total flavonoid content of vegetables was shown in Figure 2, from which it could be found that there was a much larger variation in total flavonoids than total phenolics, ranging from as high as $458 \pm 47 \mathrm{mg}$ of CE/100 $\mathrm{g}$ in red hyacinth bean to as low as $1.95 \pm 0.05 \mathrm{mg}$ of $\mathrm{CE} / 100 \mathrm{~g}$ in green pumpkin, with the difference of 234fold. Thus, similar to total phenolics, the vegetables were also divided into four groups, namely very high (>150 mg of CE/100 g), high (50 150 mg of CE/100 g), medium (10 50 mg of CE/100 g) and low (< $10 \mathrm{mg}$ of CE/100 g). The very high group was represented by red hyacinth bean; purple cabbage, red edible amaranth and purple eggplant $(318 \pm 12,315 \pm 31$ and $286 \pm 31 \mathrm{mg}$ of CE /100 g, respectively); and lotus root, Chinese flowering cabbage and Chinese kale $(189 \pm 9,177 \pm 16$ and $176 \pm 10 \mathrm{mg}$ of CE /100 g, respectively). For high flavonoid group, there were 8 vegetables: water spinach, celery and romaine lettuce $(133 \pm 5,125 \pm 11$ and $120 \pm 12 \mathrm{mg}$ of CE/100 g, respectively); and Shanghai pakchoi (70.5 $\pm 7.7 \mathrm{mg}$ of CE/100 g), broccoli (69.3 $\pm 6.5 \mathrm{mg}$ of CE/100 g), Chinese chive $(67.7 \pm 6.3 \mathrm{mg}$ of $\mathrm{CE} / 100 \mathrm{~g})$, and green chili pepper (65.5 $\pm 5.8 \mathrm{mg}$ of $\mathrm{CE} / 100 \mathrm{~g})$, which were similar (p > $0.05)$. For group with moderate total flavonoids, there were 12 vegetables: potato $(46.4 \pm 2.9 \mathrm{mg}$ of CE/100 g), shiitake mushroom (45.7 $\pm 4.2 \mathrm{mg}$ of CE/100 g), malabar spinach $(43.6 \pm 4.5 \mathrm{mg}$ of CE/100 g), purple onion (39 \pm $2.8 \mathrm{mg}$ of CE/100 g), green bell pepper ( $43 \pm 3.3 \mathrm{mg}$ of $\mathrm{CE} / 100 \mathrm{~g})$, leaf lettuce $(35.7 \pm 3 \mathrm{mg}$ of CE/100 g), carrot $(29.5 \pm 0.4 \mathrm{mg}$ of $\mathrm{CE} / 100 \mathrm{~g})$, green bean $(24 \pm 1.9 \mathrm{mg}$ of $\mathrm{CE} / 100 \mathrm{~g})$, cauliflower $(23.9 \pm 2.4 \mathrm{mg}$ of $\mathrm{CE} / 100 \mathrm{~g})$, garlic sprout (21.6 $\pm 1.2 \mathrm{mg}$ of CE/100 g), bottle gourd $(16.1 \pm 1.2 \mathrm{mg}$ of CE/100 g), and long bean (10.5 \pm 0.9 $\mathrm{mg}$ of $\mathrm{CE} / 100 \mathrm{~g})$. The remaining 9 vegetables (lettuce $(9.83 \pm 0.52 \mathrm{mg}$ of $\mathrm{CE} / 100 \mathrm{~g})$, tomato $(8.81 \pm 0.50 \mathrm{mg}$ of $\mathrm{CE} / 100 \mathrm{~g})$, cucumber ( $8.19 \pm 0.83 \mathrm{mg}$ of $\mathrm{CE} / 100 \mathrm{~g}$ ), white ternip (6.96 $\pm 0.54 \mathrm{mg}$ of $\mathrm{CE} / 100 \mathrm{~g})$, Chinese cabbage $(6.48 \pm 0.49 \mathrm{mg}$ of CE/100 g), towel gourd (6.44 \pm 0.67 mg of CE/100 g), balsam pear (4.10 $\pm 0.30 \mathrm{mg}$ of CE/100 g), wax gourd (3.22 $\pm 0.30 \mathrm{mg}$ of $\mathrm{CE} / 100 \mathrm{~g})$, green pumpkin $(1.95 \pm 0.05 \mathrm{mg}$ of $\mathrm{CE} / 100 \mathrm{~g}))$ were in the low flavonoid group. For the same vegetable investigated, the total flavonoid content in our study was relatively higher and was of the different ranking order as being compared with the other reports $[11,23]$, which might be due to the different growing environments, origins or maturity levels of vegetables.

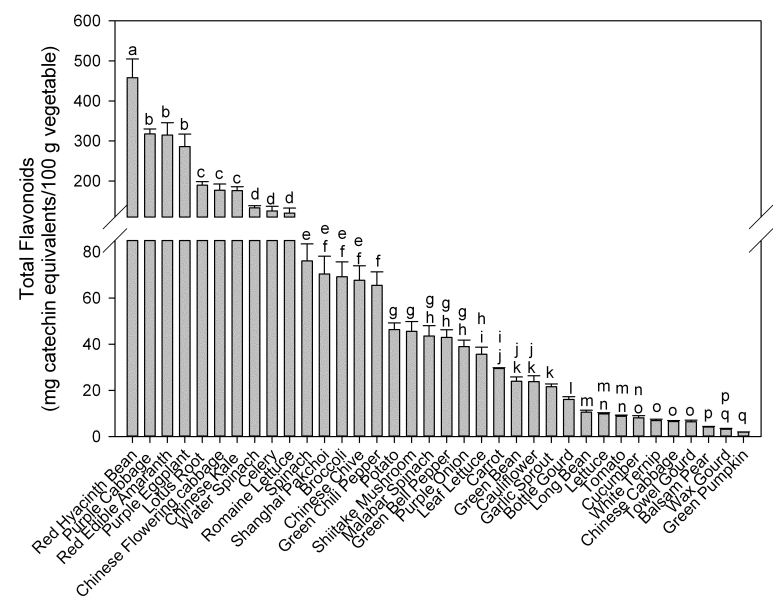

Figure 2. Total flavonoid content of selected vegetables (mean $\pm \mathrm{SD}, \mathrm{n}=$ $3)$. Bars with no letters in common are significantly different $(\mathrm{p}<0.05)$.

\subsection{ORAC}

The ORAC assay was used to evaluate the chemical antioxidant activity (peroxyl radical scavenging ability) of vegetables with the results shown in Figure 3. Among tested vegetables, purple cabbage, Chinese kale and Chinese flowering cabbage (3716 $\pm 197,3611 \pm 302$, and $3505 \pm 254 \mu \mathrm{mol}$ of $\mathrm{TE} / 100 \mathrm{~g}$, respectively) had the greatest ORAC values, while wax gourd had the lowest ORAC value $(123 \pm 12 \mu \mathrm{mol}$ of TE/ $100 \mathrm{~g})$. Based on the significant differences in their ORAC values, vegetables were divided into four groups, namely very high ( $>2000$ umol of TE/100 g), high (1000 2000 $\mu \mathrm{mol}$ of TE/100 g), medium (300 1000 $\mu$ mol of TE/100 g) and low $(<300$ $\mu$ mol of $\mathrm{TE} / 100 \mathrm{~g})$. The vegetables of the very high ORAC values included lotus root $(2617 \pm 178 \mu$ mol of TE/100 g), green chili pepper and red hyacinth bean (2394 \pm 153 and $2381 \pm 112 \mu \mathrm{mol}$ of TE/100 g, respectively), and malabar spinach $(2168 \pm 142 . \mu \mathrm{mol}$ of $\mathrm{TE} / 100 \mathrm{~g})$ except for purple cabbage, Chinese kale and Chinese flowering cabbage. The group with high ORAC values was represented by broccoli $(1505 \pm 22$. $\mu$ mol of TE/100 g); spinach (1457 $\pm 78 \mu \mathrm{mol}$ of TE/100 g); celery (1397 \pm $103 \mu \mathrm{mol}$ of TE/100 g); purple onion $(1323 \pm 38 \mu \mathrm{mol}$ of TE/100 g); long beans, red edible amaranth and Chinese chive $(1283 \pm 112,1253 \pm 68$ and $1236 \pm 88$. $\mu$ mol of TE/100 g, respectively); Shanghai pakchoi (1198 \pm 59 . $\mu \mathrm{mol}$ of $\mathrm{TE} / 100 \mathrm{~g})$; potato $(1136 \pm 104 . \mu \mathrm{mol}$ of TE/100 g); and garlic sprout $(1026 \pm 109 \mu \mathrm{mol}$ of TE/100 g). The group with moderate ORAC values was represented by purple eggplant $(961 \pm 99 \mu \mathrm{mol}$ of TE/100 g), water spinach (851 $\pm 21 \mu \mathrm{mol}$ of TE/100 g), shiitake mushroom ( $660 \pm 55 \mu \mathrm{mol}$ of TE/100 g), green bean (555 $\pm 50 \mu \mathrm{mol}$ of TE/100 g), romaine lettuce and white ternip (547 \pm 48 and $536 \pm 40 . \mu \mathrm{mol}$ of TE/100 g, respectively), cauliflower (499 $\pm 44 \mu \mathrm{mol}$ of TE/100 g), and green bell 
pepper (382 $\pm 13 \mu \mathrm{mol}$ of TE/100 g). The rest vegetables represented the low ORAC value group: tomato $(298 \pm 19$ $\mu \mathrm{mol}$ of TE/100 g), leaf lettuce $(282 \pm 28 \mu \mathrm{mol}$ of TE/100 g), green pumpkin $(267 \pm 27 \mu \mathrm{mol}$ of TE/100 g), Chinese cabbage $(250 \pm 27 . \mu \mathrm{mol}$ of $\mathrm{TE} / 100 \mathrm{~g})$, carrot $(247 \pm 2$ $\mu \mathrm{mol}$ of $\mathrm{TE} / 100 \mathrm{~g})$, bottle gourd $(240 \pm 11 . \mu \mathrm{mol}$ of TE/100 g), lettuce $(184 \pm 9 \mu \mathrm{mol}$ of TE/100 g), towel gourd $(163 \pm 16 \mu \mathrm{mol}$ of TE/100 g), cucumber $(154 \pm 11$ $\mu \mathrm{mol}$ of TE/100 g), balsam pear $(151 \pm 16 . \mu \mathrm{mol}$ of TE/100 g) and wax gourd. ORAC values for lettuce, tomato, cucumber broccoli, potato and onion were in consistent with the previous reports $[13,15]$. For the same vegetables investigated, the ranking order of ORAC values in our study was in consistent with the report by Cao et al [24], despite of the observation of higher values in our study, probably due to the choice of different fluorescent probes in the ORAC assay.

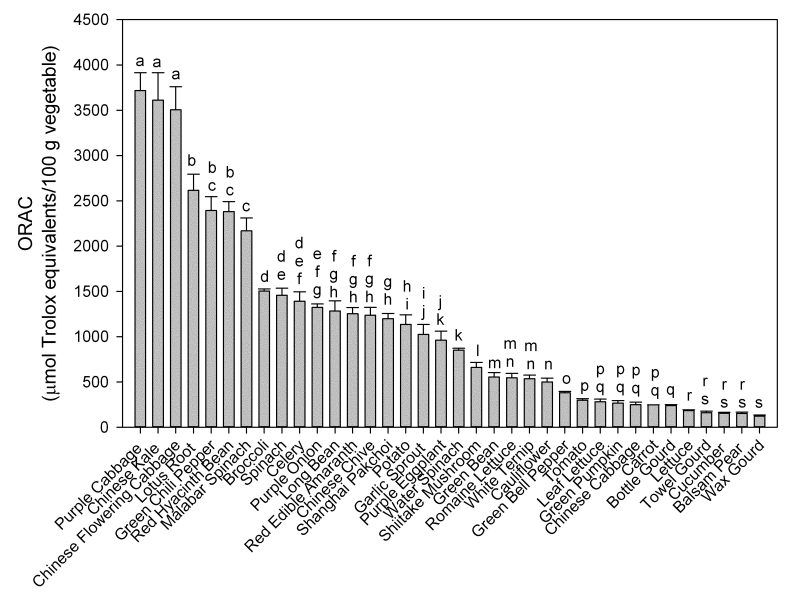

Figure 3. ORAC values of selected vegetables (mean $\pm S D, n=3$ ). Bars with no letters in common are significantly different $(\mathrm{p}<0.05)$.

\subsection{Caco-2 cell-based Antioxidant Activity (CAA)}

The Caco-2 cell-based antioxidant activity for vegetables was expressed as $\mathrm{EC}_{50}$ (Table 1) and CAA values (Figure 4), with only 13 in 36 selected vegetables quantifiable. Lotus root (37 $\pm 3.7 \mu \mathrm{mol}$ of $\mathrm{QE} / 100 \mathrm{~g})$ had the highest CAA value, followed by green chili pepper (28.2 $\pm 2.5 \mu \mathrm{mol}$ of QE/100 g). The other quantifiable vegetables possessed the CAA values with no more than 4 $\mu \mathrm{mol}$ of QE/100 g: $3.13 \pm 0.16 \mu \mathrm{mol}$ of QE/100 g (balsam pear), $2.47 \pm 0.18 \mu \mathrm{mol}$ of $\mathrm{QE} / 100 \mathrm{~g}$ (malabar spinach), $2.18 \pm 0.12 \mu \mathrm{mol}$ of $\mathrm{QE} / 100 \mathrm{~g}$ (red edible amaranth), 2.06 $\pm 0.06 \mu \mathrm{mol}$ of $\mathrm{QE} / 100 \mathrm{~g}$ (broccoli), $1.59 \pm 0.01 \mu \mathrm{mol}$ of $\mathrm{QE} / 100 \mathrm{~g}$ (purple onion), $1.32 \pm 0.12 \mu \mathrm{mol}$ of $\mathrm{QE} / 100 \mathrm{~g}$ (Chinese kale), $0.576 \pm 0.019 \mu \mathrm{mol}$ of QE/100 g (potato), $0.571 \pm 0.020 \mu \mathrm{mol}$ of $\mathrm{QE} / 100 \mathrm{~g}$ (Shanghai pakchoi), $0.484 \pm 0.020 \mu \mathrm{mol}$ of $\mathrm{QE} / 100 \mathrm{~g}$ (celery), $0.471 \pm 0.043$ $\mu \mathrm{mol}$ of $\mathrm{QE} / 100 \mathrm{~g}$ (red hyacinth bean), and $0.376 \pm 0.053$ $\mu \mathrm{mol}$ of $\mathrm{QE} / 100 \mathrm{~g}$ (green bell pepper). For the rest vegetables (bottle gourd, carrot, cauliflower, Chinese cabbage, Chinese chive, Chinese flowering cabbage, cucumber, garlic sprout, green bean, green pumpkin, leaf lettuce, lettuce, long bean, purple cabbage, purple eggplant, romaine lettuce, shiitake mushroom, spinach, tomato, towel gourd, water spinach, wax gourd and white ternip), the Caco-2 cell-based antioxidant activity was too low to be detected. Green bean and cucumber also showed no cellular antioxidant activity based on HepG2 cell model [15].

Table 1. Caco-2 cell-based antioxidant activities of selected vegetables expressed as $\mathrm{EC}_{50}$ and their cytotoxic concentrations

\begin{tabular}{|c|c|c|}
\hline Vegetable & $\mathrm{EC}_{50}(\mathrm{mg} / \mathrm{mL})$ & $\mathrm{CC}_{50}(\mathrm{mg} / \mathrm{mL})$ \\
\hline Lotus root & $37.0 \pm 5.4$ & $>400$ \\
\hline Green chili pepper & $48.4 \pm 3.3$ & $>400$ \\
\hline Balsam pear & $435 \pm 22$ & $>400$ \\
\hline Malabar spinach & $552 \pm 27$ & $>400$ \\
\hline Red edible amaranth & $624 \pm 45$ & $>400$ \\
\hline Broccoli & $662 \pm 43$ & $>400$ \\
\hline Purple onion & $856 \pm 38$ & $>400$ \\
\hline Chinese kale & $1026 \pm 39$ & $>400$ \\
\hline Potato & $2359 \pm 36$ & $>400$ \\
\hline Shanghai pakchoi & $2384 \pm 184$ & $>400$ \\
\hline Celery & $2809 \pm 52$ & $>400$ \\
\hline Red hyacinth bean & $2895 \pm 183$ & $>400$ \\
\hline Green bell pepper & $3576 \pm 332$ & $>400$ \\
\hline Other vegetables & NQ & $>400$ \\
\hline
\end{tabular}

$\mathrm{NQ}, \mathrm{EC}_{50}$ is not quantifiable due to low activity.

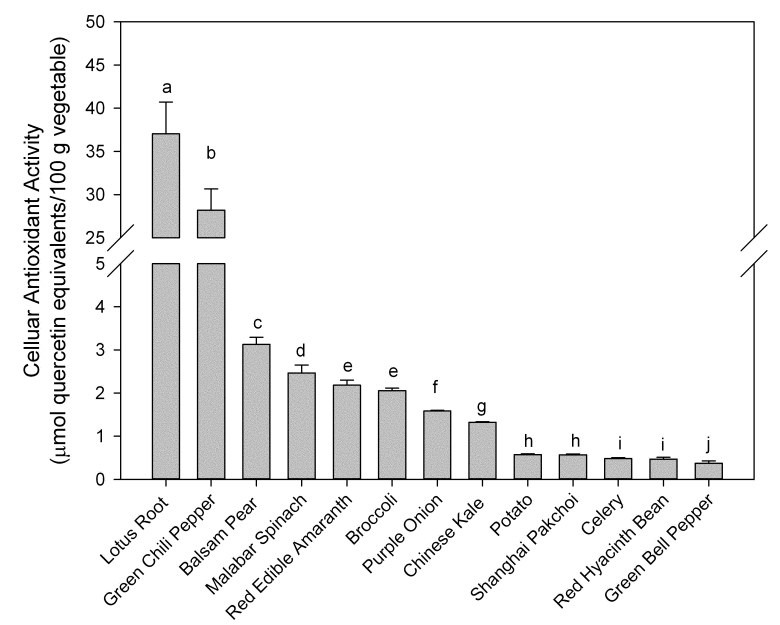

Figure 4. CAA values of quantifiable vegetables (mean $\pm S D, n=3$ ). Bars with no letters in common are significantly different $(\mathrm{p}<0.05)$.

\subsection{Correlation Analysis}

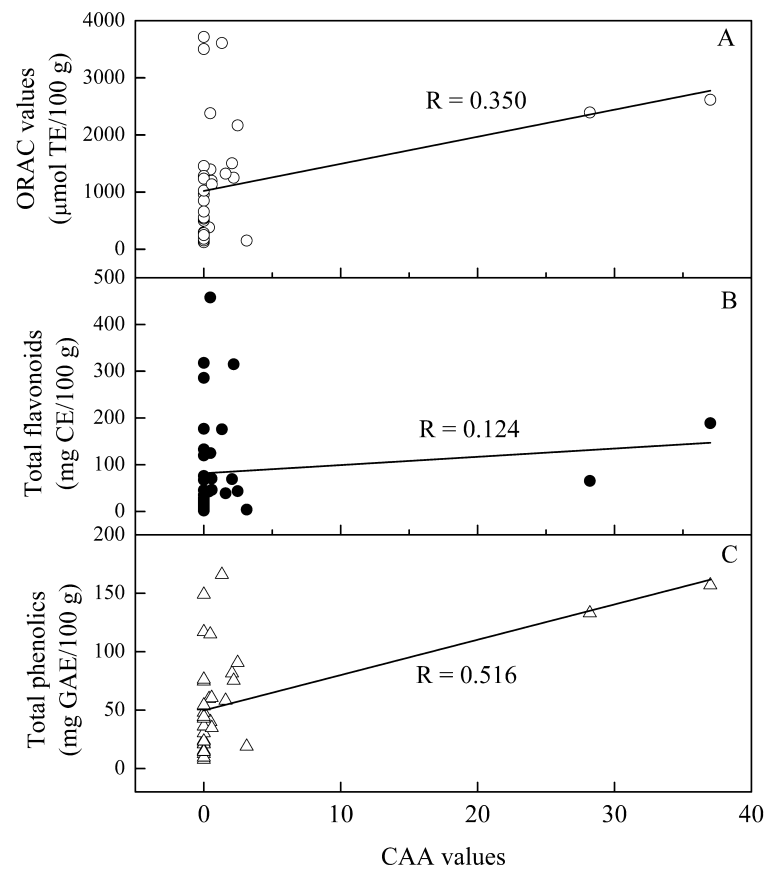

Figure 5. Correlation between CAA values and ORAC values (A), total flavonoids (B), or total phenolics (C). 
The relationship between CAA values and ORAC values or phytochemical contents (total phenolics and total flavonoids) for tested vegetables were analyzed using bivariate correlation analysis, with the result shown in Figure 5. CAA values were significantly correlated to ORAC values $(\mathrm{R}=0.350, \mathrm{p}<0.05)$ and highly significantly correlated to total phenolics $(\mathrm{R}=0.516, \quad \mathrm{p}<$ 0.01 ), whereas total flavonoids for vegetables showed no significant correlation with CAA values $(\mathrm{R}=0.124$, $\mathrm{p}>$ 0.05).

\subsection{Caco-2 cell-based Antioxidant Quality}

According to the literature described previously [15], the Caco-2 cell-based antioxidant quality of vegetables (Figure 6) was calculated from their CAA values and total phenolic contents, and expressed as micromoles of quercetin equivalents (QE) per $100 \mu \mathrm{mol}$ of phenolic compounds. Lotus root $(4.02 \pm 0.40 \mu \mathrm{mol}$ of $\mathrm{QE} / 100$ $\mu \mathrm{mol})$ had the highest antioxidant quality, followed by green chili pepper $(3.60 \pm 0.31 \mu \mathrm{mol}$ of $\mathrm{QE} / 100 \mu \mathrm{mol})$ and balsam pear $(2.82 \pm 0.15 \mu \mathrm{mol}$ of QE/100 $\mu \mathrm{mol})$. Green chili pepper was not significantly different from lotus root or balsam pear. Red edible amaranth $(0.493 \pm$ $0.026 \mu \mathrm{mol}$ of QE/100 $\mu \mathrm{mol})$ was next, and followed by purple onion and malabar spinach $(0.464 \pm 0.003$ and $0.463 \pm 0.034 \mu \mathrm{mol}$ of $\mathrm{QE} / 100 \mu \mathrm{mol}$, respectively), broccoli $(0.428 \pm 0.013 \mu \mathrm{mol}$ of $\mathrm{QE} / 100 \mu \mathrm{mol})$, potato $(0.281 \pm 0.009 \mu \mathrm{mol}$ of $\mathrm{QE} / 100 \mu \mathrm{mol})$, celery $(0.206 \pm$ $0.009 \mu \mathrm{mol}$ of $\mathrm{QE} / 100 \mu \mathrm{mol})$, Shanghai pakchoi and Chinese kale $(0.160 \pm 0.005$ and $0.136 \pm 0.001 \mu \mathrm{mol}$ of $\mathrm{QE} / 100 \mu \mathrm{mol}$, respectively), green bell pepper (0.107 \pm $0.015 \mu \mathrm{mol}$ of $\mathrm{QE} / 100 \mu \mathrm{mol})$ and red hyacinth bean $(0.0062 \pm 0.0006 \mu \mathrm{mol}$ of $\mathrm{QE} / 100 \mu \mathrm{mol})$.

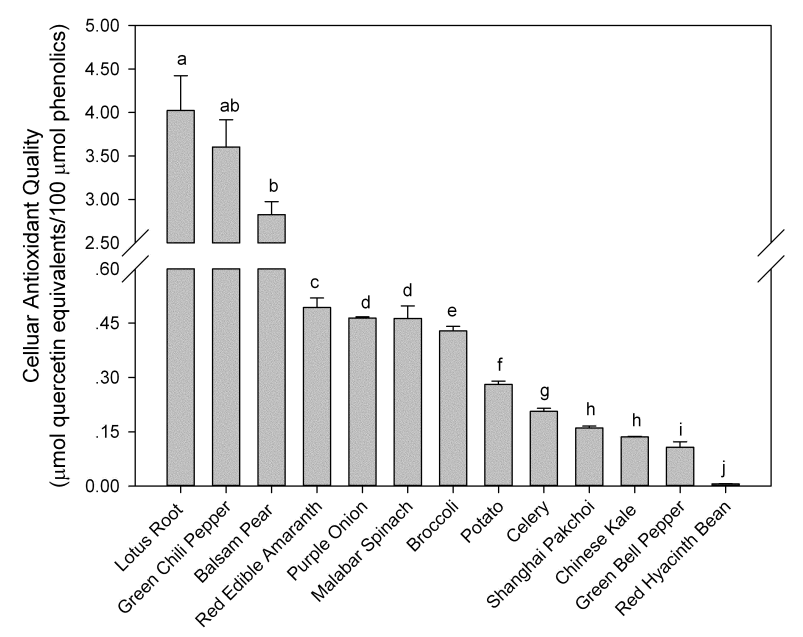

Figure 6. Caco-2 cell-based antioxidant quality of 13 vegetable phenols in the Caco-2 cell-based antioxidant activity assay (mean $\pm S D, n=3$ ). Bars with no letters in common are significantly different $(p<0.05)$.

\section{Discussion}

The Caco-2 cell-based antioxidant activity assay is an effective tool to predict the antioxidant activity of phytochemicals in vivo since the assay has been proved to possess the good biological relevance (shown in another submitted manuscript), which might be attributed to the good correlation between in vitro absorption in Caco-2 cellular model and in vivo intestinal absorption $[8,9]$.
Thirty-six vegetables commonly consumed in China were evaluated for their antioxidant ability in the Caco-2 cell-based antioxidant activity assay. Among the 36 tested vegetables, only 13 vegetables were of the quantifiable CAA values (Figure 4). Lotus root, in very high group for total phenolics, total flavonoids and ORAC values, had the highest CAA value. Green chili pepper, ranking 4th in total phenolics, 15th in total flavonoids and 6th in ORAC values among tested vegetables, showed the second highest CAA value. The relatively high antioxidant activity of green pepper was also observed in FRAP assay [25]. Balsam pear, with the much lower CAA value than green chili pepper and lotus root, ranked 3rd in CAA values despite that it was of low total phenolics, low total flavonoids and possessed the low peroxyl radical scavenging activity among all analyzed vegetables. Additionally, balsam pear was also the only vegetable with the detected CAA values among all vegetables in the low group of total phenolics, total flavonoids or ORAC values. Unlike malabar spinach, red edible amaranth, broccoli, purple eggplant and Chinese kale, which showed relatively high CAA values as well as total phenolics, total flavonoids and total ORAC values, red hyacinth bean had the low CAA value and spinach possessed no quantifiable CAA value in spite of their high levels in total phenolics, total flavonoids and total ORAC values. It is noteworthy that spinach showed very strong toxicity on Caco-2 cells, and thus its Caco-2 cell-based antioxidant activity could not be determined. Despite of relatively low ranking in total phenolics, celery and potato ranked relatively highly in CAA values as well as total flavonoids and ORAC values. Vegetables like lettuce, carrot, bottle gourd, wax gourd, towel gourd and cucumber, which showed low ORAC values and unquantifiable CAA values, were also reported to possess the low antioxidant activity among vegetables in TOSC assay, FRAP assay, TRAP assay, inhibition of lipoprotein oxidation assay, $\beta$-carotene bleaching assay, ABTS/DPPH radical scavenging assay and phosphomolybdenum assay [10,11,12, 14,21,22].

The CAA values for vegetables were positively correlated to total phenolics and ORAC values, and were not significantly correlated with total flavonoids. The correlation coefficient for CAA values and total phenolics was $R=0.516(p<0.01)$, higher than that for CAA values and ORAC values $(\mathrm{R}=0.350, \mathrm{p}<0.05)$, demonstrating that total phenolic content was a better predictor for the Caco-2 cell-based antioxidant activity of vegetables than ORAC value, despite that ORAC assay measured the peroxyl radical scavenging activity, similar to the CAA assay.

Considering that the significantly positive correlation between CAA values and total phenolic content $(\mathrm{p}<0.05)$ was not strong $(\mathrm{R}=0.516)$, an objective index of antioxidant quality, a measure of the Caco-2 cell-based antioxidant activity provided by $100 \mu \mathrm{mol}$ of phenolics in vegetables, was used in this study to assess the relative potency of the antioxidants present in vegetables. Lotus root and green chili pepper were of the highest CAA quality. Balsam pear, ranking 3rd in CAA quality, showed no significant difference with green chili pepper, suggesting the equivalent antioxidant potency of phenols in balsam pear and green chili pepper. Thus, it could be deduced that the much higher CAA value of green chili pepper than balsam pear was due to the much higher total phenolics in green chili pepper. The phenols in red 
hyacinth bean were of the lowest antioxidant quality among the quantifiable vegetable phenols, thus, it was not surprising that red hyacinth bean had low CAA value despite of very high total phenolics.

\section{Conclusion}

In this study, 36 commonly consumed vegetables in China were evaluated for their Caco-2 cell-based antioxidant activity. Among them, 13 vegetables showed quantifiable CAA values with the highest value of $37 \pm$ $3.7 \mu \mathrm{mol}$ of QE/ $100 \mathrm{~g}$ in lotus root and lowest value of $0.376 \pm 0.053 \mu \mathrm{mol}$ of $\mathrm{QE} / 100 \mathrm{~g}$ in green bell pepper. Total phenolics, total flavonoids and ORAC values for selected vegetables were also measured. CAA values were significantly correlated to ORAC values $(\mathrm{R}=0.350, \mathrm{p}<$ 0.05 ) and highly significantly correlated to total phenolics $(\mathrm{R}=0.516, \mathrm{p}<0.01)$, whereas total flavonoids for vegetables showed no significant correlation with CAA values $(R=0.124, p>0.05)$, suggesting a better predictor of total phenolics than ORAC values and total flavonoids for the Caco-2 cell-based antioxidant activity of vegetables. Determination of Caco-2 cell-based antioxidant activity of vegetables is important in screening of vegetables for potential health benefits since the assay was of good biological relevance. Thus, the results shown in this study could provide new knowledge about the health benefits of vegetables and new guidance for consumers to plan antioxidant diets so as to protect the body against oxidative stressors.

\section{Acknowledgement}

We are grateful for the financial support from Guangdong Natural Science Foundation (No.S 2011010004455), Shenzhen Science and Technology Plan Project (No. JC201005280530A) and GDHVPS (2011).

\section{Abbreviations}

AAPH: 2,2'-azobis(2-methylpropionamidine) dihydro chloride; AUC: area under the fluorescence versus time curve; CAA: Caco-2 cell-based antioxidant activity; CE: catechin equivalents; DCF: dichlorofluorescein; DCFH: 2',7'-dichlorofluorescin; DCFH-DA: 2',7'-dichloro fluorescin diacetate; DMEM: Dulbecco's Modified Eagle Medium; DMSO: dimethyl sulfoxide; FBS: fetal bovine serum; FRAP: ferric reducing/antioxidant power; GAE: gallic acid equivalents; HBSS: Hanks' Balanced Salt Solution; Hepes: 4-(2-hydroxyethyl)-1-piperazine ethane sulfonic acid; ORAC: oxygen radical absorbance capacity; $\mathrm{QE}$ : quercetin equivalents; TE: trolox equivalents; TOSC: total oxyradical scavenging capacity; TRAP: total radicaltrapping antioxidant parameter.

\section{References}

[1] Stohs, S. J., "The role of free radicals in toxicity and disease," Journal of Basic and Clinical Physiology and Pharmacology, 6 (3-4). 205-228. 1995.
[2] Aruoma, O., "Free radicals, oxidative stress, and antioxidants in human health and disease," Journal of the American Oil Chemists' Society, 75 (2). 199-212. 1998.

[3] Valko, M., Leibfritz, D., Moncol, J., Cronin, M. T., Mazur, M. and Telser, J., "Free radicals and antioxidants in normal physiological functions and human disease," The International Journal of Biochemistry \& Cell biology, 39 (1). 44-84. 2007.

[4] Prior, R. L. and Cao, G., "Antioxidant phytochemicals in fruits and vegetables: Diet and health implications," HortScience, 35 (4). 588-592. 2000.

[5] Kelemen, L. E., Cerhan, J. R., Lim, U., Davis, S., Cozen, W., Schenk, M., Colt, J., Hartge, P. and Ward, M. H., "Vegetables, fruit, and antioxidant-related nutrients and risk of non-hodgkin lymphoma: A national cancer institute-surveillance, epidemiology, and end results population-based case-control study," The American Journal of Clinical Nutrition, 83 (6). 1401-1410. 2006.

[6] Hung, H.-C., Joshipura, K. J., Jiang, R., Hu, F. B., Hunter, D., Smith-Warner, S. A., Colditz, G. A., Rosner, B., Spiegelman, D. and Willett, W. C., "Fruit and vegetable intake and risk of major chronic disease," Journal of the National Cancer Institute, 96 (21). 1577-1584. 2004.

[7] Wan, H. Sun, H., Yu, X., Li, Y. and Liu, D., "Development and validation of a Caco-2 cell-based quantitative antioxidant activity assay for antioxidants," Food Chemistry, submitted. 2014.

[8] Artursson, P. and Karlsson, J., "Correlation between oral-drug absorption in humans and apparent drug permeability coefficients in human intestinal epithelial (caco-2) cells," Biochemical and Biophysical Research Communications, 175 (3). 880-885. 1991.

[9] Liu, C. S., Glahn, R. P. and Liu, R. H., "Assessment of carotenoid bioavailability of whole foods using a caco-2 cell culture model coupled with an in vitro digestion," Journal of Agricultural and Food Chemistry, 52 (13). 4330-4337. 2004.

[10] CK, R., KL, R., KS, J., Joyce, G. S., Mala, R.-S. V. and BR, V. A. "Comparative evaluation of antioxidant property in methanol extracts of some common vegetables of india," Annals of Biological Research, 2 (2). 86-94. 2011.

[11] Chun, O. K., Kim, D.-O., Smith, N., Schroeder, D., Han, J. T. and Lee, C. Y., "Daily consumption of phenolics and total antioxidant capacity from fruit and vegetables in the american diet," Journal of the Science of Food and Agriculture, 85 (10). 1715-1724. 2005.

[12] Pellegrini, N., Serafini, M., Colombi, B., Del Rio, D., Salvatore, S., Bianchi, M. and Brighenti, F., "Total antioxidant capacity of plant foods, beverages and oils consumed in italy assessed by three different in vitro assays," The Journal of Nutrition, 133 (9). 28122819. 2003.

[13] Wu, X., Beecher, G. R., Holden, J. M., Haytowitz, D. B., Gebhardt, S. E. and Prior, R. L., "Lipophilic and hydrophilic antioxidant capacities of common foods in the united states," Journal of Agricultural and Food Chemistry, 52 (12). 4026-4037. 2004.

[14] Chu, Y. F., Sun, J., Wu, X. Z. and Liu, R. H., "Antioxidant and anti proliferative activities of common vegetables," Journal of Agricultural and Food Chemistry, 50 (23). 6910-6916. 2002.

[15] Song, W., Derito, C. M., Liu, M. K., He, X., Dong, M. and Liu, R. H., "Cellular antioxidant activity of common vegetables," Journal of Agricultural and Food Chemistry, 58 (11). 6621-6629. 2010.

[16] Dewanto, V., Wu, X., Adom, K. K. and Liu, R. H., "Thermal processing enhances the nutritional value of tomatoes by increasing total antioxidant activity," Journal of Agricultural and Food Chemistry, 50 (10). 3010-3014. 2002.

[17] Wolfe, K. L. and Liu, R. H., "Cellular antioxidant activity (caa) assay for assessing antioxidants, foods, and dietary supplements," Journal of Agricultural and Food Chemistry, 55 (22). 8896-8907. 2007.

[18] Singleton, V. L., Orthofer, R. and Lamuela-Raventós, R. M., "Analysis of total phenols and other oxidation substrates and antioxidants by means of folin-ciocalteu reagent," Methods in Enzymology, 299. 152-178. 1999.

[19] Jia, Z., Tang, M. and Wu, J., "The determination of flavonoid contents in mulberry and their scavenging effects on superoxide radicals," Food Chemistry, 64 (4). 555-559. 1999.

[20] Huang, D. J., Ou, B. X., Hampsch-Woodill, M., Flanagan, J. A. and Prior, R. L., "High-throughput assay of oxygen radical absorbance capacity (orac) using a multichannel liquid handling system coupled with a microplate flourescence reader in 96-well format," Journal of Agricultural and Food Chemistry, 50 (16). 4437-4444. 2002. 
[21] Kaur, C. and Kapoor, H. C., "Anti-oxidant activity and total phenolic content of some asian vegetables," International Journal of Food Science \& Technology, 37 (2). 153-161. 2002.

[22] Vinson, J. A., Hao, Y., Su, X. and Zubik, L., "Phenol antioxidant quantity and quality in foods: Vegetables," Journal of Agricultural and Food Chemistry, 46 (9). 3630-3634. 1998.

[23] Miean, K. H. and Mohamed, S., "Flavonoid (myricetin, quercetin, kaempferol, luteolin, and apigenin) content of edible tropical plants," Journal of Agricultural and Food Chemistry, 49 (6) 3106-3112. 2001.

[24] Cao, G., Sofic, E. and Prior, R. L., "Antioxidant capacity of tea and common vegetables," Journal of Agricultural and Food Chemistry, 44 (11). 3426-3431. 1996.

[25] Halvorsen, B. L., Holte, K., Myhrstad, M. C., Barikmo, I., Hvattum, E., Remberg, S. F., Wold, A. B., Haffner, K., Baugerod, H., Andersen, L. F., Moskaug, O., Jacobs, D. R., Jr. and Blomhoff, R., "A systematic screening of total antioxidants in dietary plants," The Journal of Nutrition, 132 (3). 461-471. 2002. 